\title{
Kameradan Alınan Görüntünün CNC Tezgâhında Gerçek Zamanlı Olarak İșlenmesi
}

\author{
Sitkı ÖZTÜRK ${ }^{1}$, Melih KUNCAN ${ }^{2 *}$ \\ ${ }^{1}$ Kocaeli Üniversitesi, Elektronik Haberleşme Mühendisliği, Kocaeli \\ ${ }^{2}$ Siirt Üniversitesi, Elektrik-Elektronik Mühendisligi, Siirt \\ (ORCID: 0000-0003-3804-5581) (ORCID: 0000-0002-9749-0418)
}

\begin{abstract}
Özet
Bu çalışmada endüstride yaygın olarak kullanılan bilgisayar destekli sayısal kontrolöre (CNC (Computer Numerik Control)) koordinat desteği ile görüntünün ölçekli olarak çizdirilmesi hedeflenmiştir. Bilgisayar ortamında alınan görüntünün görsel olarak benzetiminden sonra elde edilen iskelet yörünge koordinatları, CNC hareket yörünge komutlarına dönüştürülmekte ve CNC ünitesine yüklenen hareket komutları makinede otomatik olarak işlenmektedir. Bu çalışma sayesinde görüntü işlemenin kullanım alanları ile programlanabilir makinelerin çalışma alanları birleştirilerek, yararlı bir çalışma oluşturulması amaçlanmıştır. Görüntünün kameradan alınarak, üzerinde belirli işlemlerin uygulanılması sonucunda, kullanılacak gerekli bilgiler alınmıştır. Bunun için sırasıyla alınan görüntüye belirli bir eşik değeri uygulanarak siyah beyaz (binary) bir görüntü oluşturulmuş ve iskelet çıkarımları yapılarak görüntünün koordinat değerleri elde edilmiştir. Bu çalışmada, iskelet çıkarımı için Matlab programında görüntünün iskeletini oluşturma (skeleton) fonksiyonundan yararlanılmış, koordinat değerleri ise sınır çıkarma fonksiyonları ile (bwboundaries) belirlenmiştir. Elde edilen koordinat değerlerini CNC'de hareket komutuna dönüştürebilmek için 'g kod' una dönüştürmek gerekmektedir. Bu işlem basamağı Matlab programı kullanılarak gerçekleştirilmiştir. g kodu çıktı dosyası USB bellek yardımı ile CNC'ye aktarılarak x-y düzleminde görüntüyü istenen şekilde talaş kaldırarak çizdirilmiştir. Sonuç olarak bu çalışmada, kameradan alınan görüntünün koordinatlarının hesaplanması sayesinde istenen şekilde CNC tezgah tarafindan işlemenin yapılması amaçlanmıştır. Görüntü işleme aşamasında Matlab programı kullanılmış, işlenen görüntüyü istenen şekilde talaş kaldırarak çizdirebilmek için Siemens'in Sinumerik CNC tezgâhı kullanılmıştır. Prototip makinede gerçekleştirilen işleme çıktıları üzerinde yapılan ölçüm testleri sonucunda işlemenin orijinal resme uygun hatasız bir şekilde gerçekleştiği gözlenmiştir. Yapılan karşılaştırma ve değerlendirmelerde teorik sonuçlarla pratik sonuçların büyük oranda örtüştüğü sonucuna varılmıştır.
\end{abstract}

Anahtar kelimeler: Görüntü işleme, g kod, CNC makine, gerçek zamanlı işleme.

\section{Real-Time Processing of the Image Taken from the Camera on the CNC Machine}

\begin{abstract}
The aim of this study is to plot the image with the CNC (Computer Numeric Control) co-ordinated support, which is a common practice in the industry. The movement commands loaded on to the device are performed automatically on the device. The aim of this work is to combine the areas of use of image processing and the working areas of programmable machines in order to create useful work. The image is obtained from the camera and the necessary information obtained as a result of individual operations. To this end, a black-and-white (binary) picture was developed by adding a specific limit value to the picture, and the skeleton inferences were achieved and the coordinate values of the picture were acquired. In this study, the skeleton function was used for skeleton extraction in the Matlab program and the boundary was determined by the coordinate values. It is essential to transform the acquired coordinate values to' $\mathrm{g}$ code' in order to transform them to CNC movement commands. This phase has been finished with the Matlab program. The g code output file is transferred to the CNC with the help of the USB memory, and the image is drowned plotted in the $\mathrm{x}-\mathrm{y}$ plane by removing the chips as desired. As a result, the aim of this study is to conduct the machining of the CNC machine as required by calculating the picture coordinates drawn from the camera. The Matlab program was used at the image processing stage and the Siemens Sinumerik CNC machine was used to write the machined picture as requested. The machining was carried
\end{abstract}

*Sorumlu yazar: melihkuncan@siirt.edu.tr

Gelis Tarihi: 11.09.2019, Kabul Tarihi: 16.03.2020 
out without mistake as a consequence of the assessment experiments carried out on the prototype device. In comparisons and assessments, it is found that theoretical findings and practical outcomes are in great agreement.

Keywords: Image processing, g code, CNC machine, real time machining.

\section{Giriș}

Bilim ve teknolojinin hızlı gelişmesi ile çok sayıda endüstriyel ürün ortaya çıkmış ve beraberinde farklı alanlarda yeniliklere ve yeni uygulamalara ihtiyaç doğmuştur. Bu durum yenilik ve yeni uygulamaların gelişmesine katkı sağlamıştır. Başta sanayi uygulamaları olmak üzere, günümüz imalat sektörünün vazgeçilmezi durumundaki CNC tezgâhlar üzerine çalışmalar giderek artmıştır. CNC tezgâhlar üzerine çalışmaların artmasıyla beraber CNC programlama hem akademik hem de ticari anlamda çok önem kazanmıştır.

Teknolojinin hızla gelişmesiyle birlikte sistemlerin çoğunda insan gücünün yerini teknolojik sistemler almaktadır. Teknolojik sistemlerin öneminin artmasıyla birçok endüstriyel ürünler farklı alanlarda ortaya çıkmıştır. Sanayi, savunma, sağlık, imalat, üretimin olduğu sektörler vb. birçok alanda yeni uygulamalara ihtiyaçlar doğmuştur. Bu bağlamda insanların ihtiyaç duyduğu tüketim malzemeleri otomasyon sistemleri yardımıyla daha kısa sürede, daha kaliteli, seri ve daha ucuza mal eden teknolojik araçlar imal edilmektedir. Çeşitli alanlarda ortaya çıkan ihtiyaçlar doğrultusunda başta sanayi uygulamaları olmak üzere çok sayıda çalışmanın gerçekleştirildiği görülmektedir. Bunların en başında, imalat sektöründeki yaygın uygulamalarından söz edebilir ve günümüz imalat sektörünün vazgeçilmezi durumundaki CNC tezgâhların üzerine çalışmaların arttığı görülmektedir. Bilgisayar Destekli Numerik Kontrol için kısa ad olarak kullanılan CNC tezgâh ve sistemleri, yazılı bir programa göre insanın hiçbir müdahalesi olmadan bir parçayı işleyen veya bir işi yapan sistemlerdir [1-3].

CNC tezgâhlar, konvansiyonel tezgâhların optimize edilmesi sonucu ortaya çıkan bir ürün olarak ifade edilebilmektedir. Yüksek hassasiyet ve hızlı işlem kabiliyetlerinden dolayı, imalat sektöründe CNC'ler çok geniş bir kullanım alanına sahiptirler [4, 5]. Sayısal kontrol fikri II. Dünya Savaşı'nın sonlarında ABD hava kuvvetlerinin ihtiyacı olan karmaşık uçak parçalarının üretimi sırasında ortaya atılmıştır. Bu karmaşık parçaların o günkü mevcut imalat tezgâhları ile üretilmesinin mümkün olmadığından bunun gerçekleştirilmesi için Parsons Corporation ve MIT (Massachusetts Teknoloji Enstitüsü) ortak bir çalışmayı hayata geçirmişlerdir. 1952 yılında ilk olarak CincinnattiHydrotel freze tezgâhını sayısal kontrol ile entegre ederek bu alandaki ilk başarılı çalışmayı gerçekleştirmişlerdir. Bu yıllardan sonra birçok takım tezgâhı üreticisi sayısal kontrollü tezgâh imalatına geçmişlerdir. 1970'lerden sonra, elle hazırlanan taslaklar yerine bilgisayar destekli tasarım sistemleri kullanılarak elektronik olarak hazırlama daha fazla kabiliyet sağlamaya başlamasından dolayı şirketlerin CAD'a (Computer Aided Design) geçmesinin maliyet avantajı ön plana çıkmıştır. Sonuçta CAD işlemi tasarımcıya mühendislik hesaplamaları yapma olanağı sağlamaktadır. Bu geçiş esnasında, hesaplamalar elle ya da bilgisayar programları çalıştıran kişilerce gerçekleştirilmektedir. CAD, taslak, tasarımcı ve mühendislik rollerinin birleşmeye başladığı mühendislik alanında giderek önemi artmaktadır. Ayrıca bazı CAD yazılımları dinamik matematiksel modelleme yeteneğine sahiptir ve bunun sonucunda CAD yazılımı olarak pazarlanabilmektedirler. CAD teknolojisi, küçük konutlardan en geniş ticari ve endüstriyel yapılara (hastaneler, fabrikalar vb.) kadar her türlü binanın tasarım ve taslağı hazırlanırken aynı zamanda araç ve makine tasarımında da yaygın olarak kullanılmaktadır. CAD, genel olarak, 3B modellerin ve/veya 2B fiziksel bileşenlerin çizimlerinin ayrıntılı mühendisliği için kullanılır; ancak, bileşenlerin kuvvet ve dinamik analizi ile bileşenlerin üretim yöntemlerinin tanımlanmasına kadar, kavramsal tasarım ve ürün yerleşiminden mühendislik süreci boyunca da geniş bir alanda kullanımı mevcuttur. CAD, bilgisayar destekli teknolojiler kapsamında özellikle düşük maliyetli ürün geliştirme ve tasarım döngüsü kısaltılması gibi önemli bir teknoloji haline gelmiştir. CNC tezgâhlarındaki ürünün işlenmesi için CAD olarak bilinen Bilgisayar Destekli Tasarım, bir ürünün tasarımına yönelik olup, ürünün imalat resmini oluşturmaktadır. Günümüzde CAD her çeşit makine, gemi, uçak, taşıt, beyaz eşya ve her çeşit ürünlerin tasarımında geniş bir alanda kullanılmaktadır [6-7 ].

CAM olarak isimlendirilen (Computer Aided Manufacturing) Bilgisayar Destekli İmalat, esasen imalata yönelik bir sistem olarak tanımlanabilir. CAM, CAD sisteminde oluşturulan üretim resimlerine göre oluşturulacak ürünün işlenmesi için takım hareket yolunu oluşturur ve bunu CNC tezgâhların çalışması için NC programına dönüştürür. NC programının esası g-kodlarıdır. Günümüzde CAM sistemi 
CAD-CAM altında entegre olarak çalışmaktadır. Genel olarak CAD, CAM, CNC çok yakın ilişkili sistemleri tanımlamaktadır. Günümüzde CAD-CAM-CNC şeklinde bütünleşmiş durumundadırlar. $\mathrm{Bu}$ sistemlerin sonucu olarak üretim ve ürün yenilik çevrimleri çok kısa zamanda gerçekleştirilerek, çok geniş, kaliteli ve ucuz ürün yelpazesi meydana getirilmektedir. Üretim alanında çalışan herhangi bir kimsenin, CNC tezgâhları ve bunların programlanması hakkında az veya sistemi kontrol edebilecek bilgiye ihtiyacı vardır. CNC tezgâhlarda bir parçanın işlenmesi parçanın NC programında açıklanır. Buna göre program, bir parçanın tam olarak işlenmesi için tüm bilgileri içeren ve bunları tezgâhların kontrol ünitesine giriş olarak veren bir belgedir. Genelde bir programda dört çeşit bilgi vardır.

- Geometrik bilgiler. Parçanın şeklini ifade eden bilgilerdir.

- Hareket bilgileri. Takım veya parçanın yaptığı hareketlerin şeklini ve yönünü içeren bilgilerdir. Genelde CNC sistemlerin programlanmasında parça ilerleme hareket etse dahi, bu hareketler takım tarafindan yapıldı $\breve{g} 1$ varsayılır.

- Teknolojik bilgiler. Takımı, ilerleme hızını ve kesme hızını içerir.

- Yardımcı bilgiler. İş milinin hangi yönde dönmesini, takım değiştirmesini, kesme sıvısının kullanılması vb. işlemleri içerir.

Genelde CNC tezgâhları için program oluşturmak için üç yöntem vardır:

- ISO kod (g-kodu) sistemine dayanan, direkt programlama.

- APT gibi programlama dili.

- Grafik etkileşime dayanan programlar.

Bunlar; CAM adını taşıyan programlar ve bazı firmaların özel olarak geliştirdikleri ve genelde diyalog esasına dayanan programlama yöntemi şeklinde olabilirler. Programlama sistemleri ne olursa olsun şimdiki haliyle CNC tezgâhları ISO (dosya biçimi) yani g- koduna göre çalışırlar. Buna göre diğer yöntemlerle önce takım yolu oluşturulur, daha sonra postprosesör denilen bir sistemle yol bilgileri $G$ kodlarına dönüştürülür ve bu şekilde CNC tezgâha program yüklenir.

CAD-CAM sistemlerinde yukarıda bahsedilen uygulamaların yaygın bir şekilde kullanıldığ bilinmektedir. Geçmiş yıllarda NC takım tezgâhlarında vakumlu tüpler, röleler, karışık kontrol ara yüzleri kullanılmaktaydı. Ancak bu ürünlerin s1k s1k tamirleri hatta yenilenmeleri gerekmekteydi. Sonraki yıllarda NC takım tezgâhlarında daha kullanışlı olan minyatür elektronik tüp ve yekpare devreler kullanılmaya başlanmıştır. Bilgisayar teknolojisinin hızlı gelişmesi sayısal kontrollü sistemleri de önemli ölçüde etkilemiştir. Son yıllarda artık NC tezgâhlarda daha yüksek düzeyde geliştirilmiş olan entegre devre ekipmanları, uygun fiyat ve güvenilir olan donanımlar kullanılmaktadır. ROM (Read Only Memory) teknolojisinin kullanılmaya başlanmasıyla da programların hafızada saklanmaları mümkün olmuştur. Yukarıda bahsedilen sistemli gelişmeler, CNC'nin ortaya çıkmasına öncülük etmiştir. CNC sonraki yıllarda torna, matkap vb. takım tezgâhlarında yaygın olarak kullanılmaya başlanmıştır [6-7].

Görüntü işleme, ölçülmüş veya kaydedilmiş görüntü verilerini, elektronik ortamda amaca uygun şekilde değiştirmeye yönelik yapılan bilgisayar çalışmalarını kapsamaktadır [8]. Teknolojinin hızlı gelişmesi neticesinde görüntü işleme uygulamaları geniş bir alanda çalışma konusu olmuştur. Başta sanayi, askeriye, tıp, tarım, imalat sektörü olmak üzere birçok farklı alanda hem akademik hem de endüstriyel çalışmalar yaygın bir şekilde yapıldığı görülmektedir. Bu bağlamda birçok farklı düzeyde görüntü işleme çalışması mevcuttur.

İleri düzey görüntü işleme problemlerinin standart yöntemlerle çözülmesi oldukça zordur. Matlab ve Image Processing Toolbox görüntü işleme, analiz, görselleştirme ve algoritma geliştirme için oldukça kullanışlıdır.

$\mathrm{Bu}$ çalışmada, laboratuvar ortamında geliştirilen $\mathrm{CNC}$ test düzeneğinde görüntü işleme uygulamasının gerçekleştirilmesi amaçlanmıştır. Böylelikle endüstride çok önemli bir yere sahip olan CNC tezgahların görüntü işleme uygulamaları ile entegre edilerek hem akademik hem de ticari bir çalışmaya öncü olması hedeflenmiştir. Bu çalışma sayesinde gerçek zamanlı olarak kameradan alınan görüntünün, CNC tezgahta istenen hassasiyette işlenmesi gerçekleştirilmiştir. Çalışmanın ilk aşamasında CNC tezgâhının çalışma mantığı, eksen hareketleri ve motorların konumlandırılması incelenmiştir. Çalışmanın ikinci aşaması olan görüntü işleme kısmında ise oluşan ikili resimden koordinat değerlerinin hangi ölçütlere göre alınacağı belirtilmiş, CNC tezgahına bu hareket yörünge koordinat değerlerinin nasıl yükleneceğinden anlatılmıştır. Koordinat değerlerinin normalizasyon edilmesi için kullanılan algoritmasına da çalışmanın üçüncü bölümünde yer verilmiştir. 
Yapılan bu çalışma sonucunda başta imalat sektörü olmak üzere birçok sektörde kullanım potansiyeline sahip bir prototip $\mathrm{CNC}$ çalışması gerçekleştirilmiş̧ir. Çalışmanın görüntü işleme ile entegre edilerek disiplinlerarası faydalı bir çalışma gerçekleştirildiği düşünülmektedir. Çalışma kapsamında kameradan alınan bir görüntü ile Matlab üzerinde görüntü işleme alanında işlemler yapabileceği ve CNC tezgâhında parça işlemenin yapılabileceği görülmüştür. Bu işlemlerin gelişmekte olduğunu ve geliştirilebileceği, görüntü işlemenin günümüzde çoğu uygulamalara eklenebileceği elektronik cihazlar ile işbirliği içinde çalışma sağlanabileceği görülmüştür. Koordinat bulma ve bu koordinatları sıralı olarak alma konusunda detaylı araştırmalar yapılmış yeni uygulamalar ve çözümler bulunmaya çalışılmıştır. Yapılan deneysel çalışmalarda yüksek başarım oranıyla işleme olayının yapıldı̆̆ 1 belirlenmiştir.

\section{Nümerik Kontrol}

$\mathrm{Bu}$ çalışmada kullanılan modül, eksenlerin ve düzlem açıklamalarının koordinat sistemine göre atamalarını açıklamakla birlikte çalışma alanı ile ilgili noktaların tanımlanmasına da imkan vermektedir. DIN standardına göre, CNC tezgâhlarının çalışma alanındaki çeşitli hareket eksenleri harflerle ifade edilmektedir.

Koordinat sistemi, bir noktanın veya geometrik elemanın konumunu hatasız şekilde belirlemek için çoklu olarak sayıların kullanıldığı sistem olarak tanımlanmaktadır. Şekil 1'de verilen $\boldsymbol{p}$ noktasının koordinatı $\boldsymbol{p}(\boldsymbol{x}, \boldsymbol{y}, \boldsymbol{z})$ olarak Kartezyen düzlemde 3 boyutlu olarak veya $\boldsymbol{p}(\boldsymbol{r}, \boldsymbol{\theta}, \boldsymbol{\varphi})$ olarak kutupsal düzlemde verilmektedir. $\boldsymbol{x}, \boldsymbol{y}$ ve $\boldsymbol{z}$ Kartezyen düzlemin orjininden $\boldsymbol{p}$ noktasina herbir düzleme dik uzaklığını göstermektedir. Aynı şekilde kutupsal düzlemde $\boldsymbol{r}, \boldsymbol{\theta}$ ve $\boldsymbol{\varphi}$ sırasıyla koordinat mesafesi, kutup açısı ve azimut açı olarak tanımlanmaktadır. Koordinatlar, temel matematikteki reel sayılar olarak, karmaşık sayılar ya da soyut bir sistemin elemanları olabilirler.

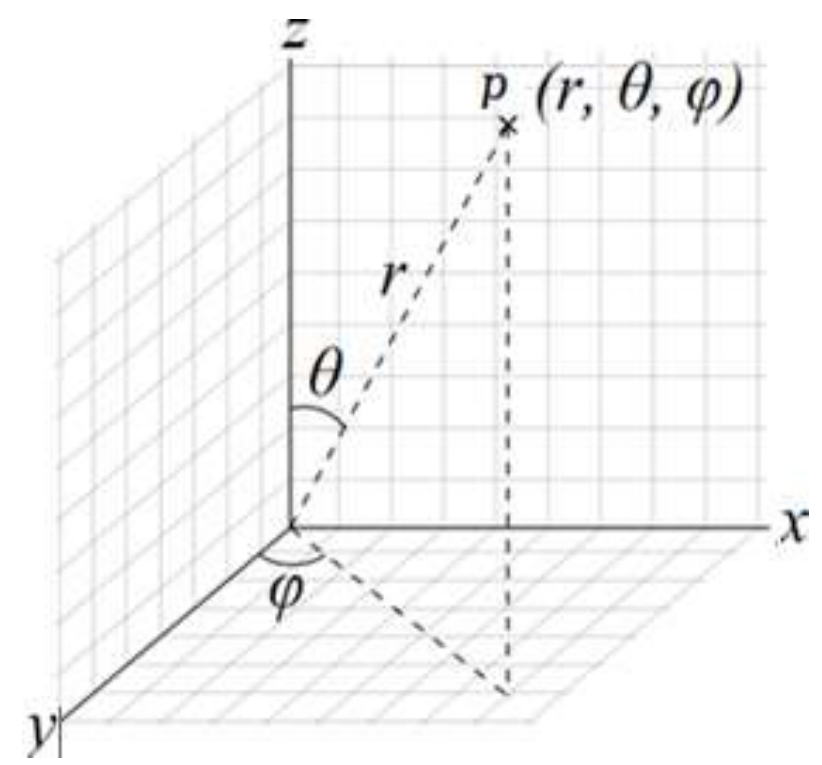

Şekil 1. Küresel koordinat sistemi kesit görüntüsü [7]

Tüm gerçek nesneler üç boyutludur. Bu nesneleri çizmek için ilk CAD sistemlerinde resimler sadece iki boyutlu olarak (2B) çizilebiliyordu. 1970'lerin sonlarında üç boyutlu görüntü veren perspektif çizimler çizilmeye başlanmıştır. Üç boyutlu çizimler önce tel kafes modeli, sonra yüzey modelleme ve özellikler 1990'lardan sonra gerçek hayattaki nesneleri temsil eden katı modelleme denilen sistemler çizilmeye başlanmıştır.

Üç boyutlu nesnelerin yüzey ve katı modellerine dayanarak, CAM sistemleri geliştirilmiştir. Katı modellemede nesnelerin hacmi, ağırlıkları ve kütlesel eylemsizlik momentleri de hesaplanır. Kısaca üç boyutlu nesnelerin ekranda görüntülenmesi yalnızca nesne şekillerinin kolay anlaşılması bakımından değil, bilgisayarlı üretim ve mühendislik analiz alanlarında kullanılmasında da çok önemli bir yere sahip 
olduğu anlaşılmaktadır. CNC sistemler Şekil 2'de gösterildiği gibi belirli bir koordinat sistemine göre çalışırlar.
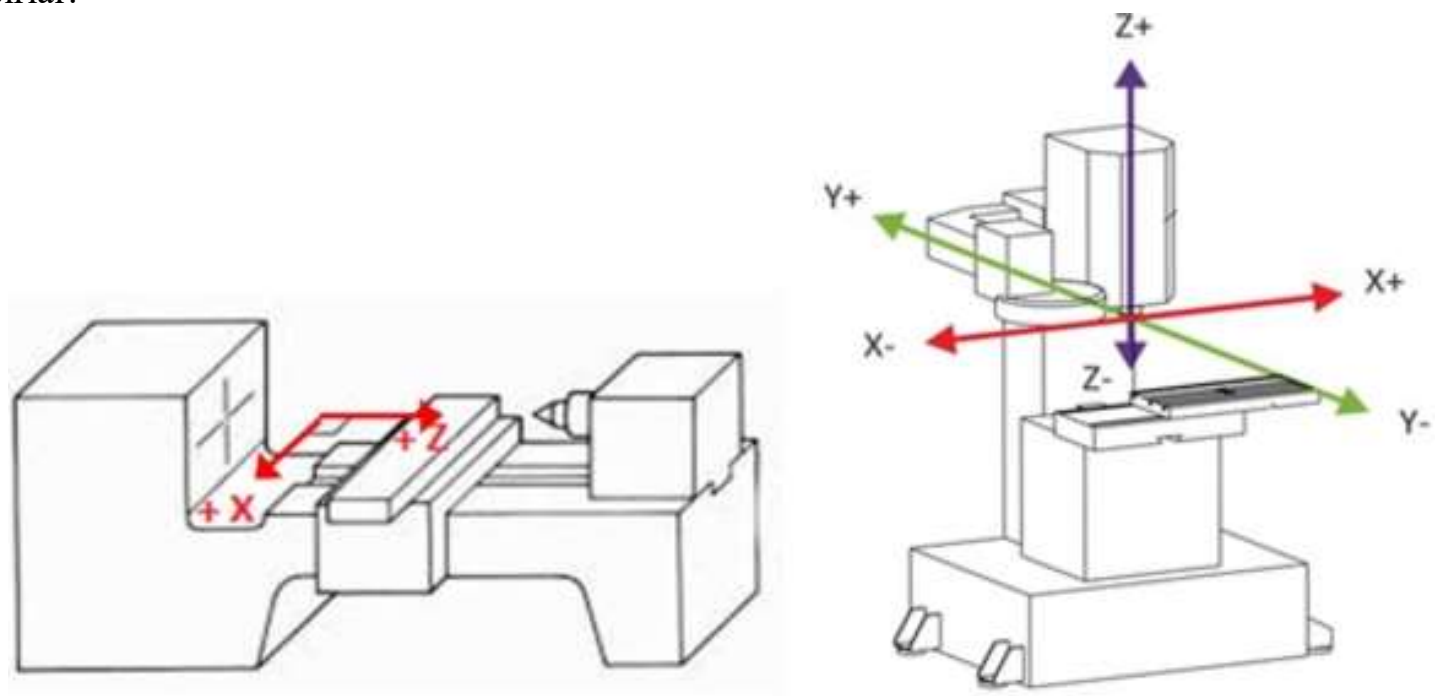

Şekil 2. CNC torna ve freze tezgâhında kullanılan temel eksenlerin gösterimleri [7]

CNC sistemlerde standart olarak kabul edilen koordinat sistemi Kartezyen koordinat sistemi olarak tanımlanmaktadır. Koordinat sistemine parçayı işlemek için takım yolu tayin edilmektedir. Parçanın geometrisini açıklayan takım yolu parça üzerindeki önemli noktalardan meydana gelmektedir. Koordinat sistemi bir noktanın düzlemde veya uzayda tam olarak yerini tayin eden bir araç olarak ifade edilmektedir. İki eksenli koordinat sistemi ele alındığında $\mathrm{X}$ ve $\mathrm{Y}$ düzlemlerindeki koordinatlar bulunmaktadır. İki eksenli koordinat sisteminin yanı sıra üç eksenli Kartezyen koordinat sistemi de bulunmaktadır. Üç eksenli koordinat sisteminin eksenleri X, Y, Z simgeleri ile ifade edilirler. XY, YZ ve $X Z$ olmak üzere üç düzlem içermektedirler. $X Y$ düzleminde $Z=0, X Z$ düzleminde $Y=0$ ve $Y Z$ düzleminde $X=0$ olarak tanımlanmaktadır. Çalışma düzlemleri de denilen bu düzlemler belirli kodlarla ifade edilmişlerdir.

CNC sistemlerinde doğrusal hareketlerin yanı sıra dönme hareketleri de mevcuttur. Buna göre $\mathrm{CNC}$ sistemlere ait koordinat sistemlerinde $\mathrm{X}, \mathrm{Y}, \mathrm{Z}$ ile gösterilen doğrusal hareket eksenlerinin yanı sıra, bu eksenlerin etrafinda dönme eksenleri de mevcuttur. Dönme eksenleri X ekseni etrafinda A, Y eksenleri etrafında $B$ ve $Z$ ekseni etrafında $C$ ile tanımlanmaktadır. Üç eksenli koordinat sistemlerinde $\mathrm{X}, \mathrm{Y}, \mathrm{Z}$ eksenlerinin yönlerini tayin etmek için genelde sağ-el kuralı kullanılmaktadır. Bu kural; X ekseni esas alındığında, $Y$ ekseni buna dik ve $Z$ ekseni $X Y$ düzleme dik olmaktadır. Eksenlerin yönleri; başparmak $+X$ yönünü, işaret parmağ $1+Y$ yönünün ve orta parmak $+Z$ ekseninin yönünü göstermektedir.
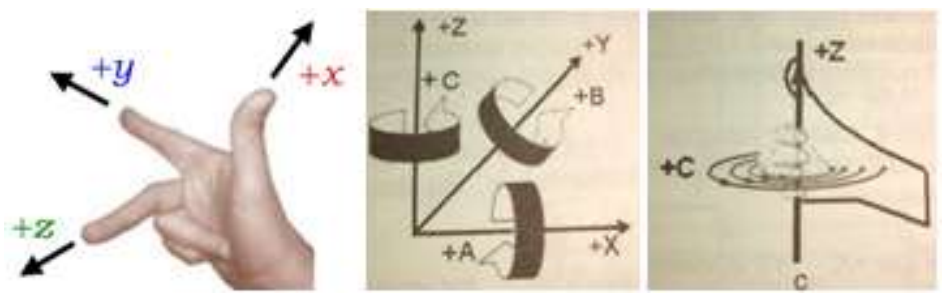

Şekil 3. Koordinat düzleminde sağ-el kuralı gösterimi [7]

$+\mathrm{A},+\mathrm{B},+\mathrm{C}$ dönme yönleri Şekil 3'te gösterilen yine sağ-el kuralı ile tayin edilmektedir. Buna göre eksen, başparmak eksenin pozitif yönünü gösterecek biçimde tüm elle kavranırsa, diğer parmakların uçları dönmenin pozitif yönünü gösterir. Şekil 3'te bu kural etrafındaki dönme ekseni C ile gösterilen $\mathrm{Z}$ eksenine uygulanmıştır.

Kartezyen koordinat sisteminin yanı sıra polar, silindirik ve küresel koordinat sistemleri de kullanılmaktadır. Bu koordinat sistemlerinin özelliği, bir noktanın yerini göstermek için eksenlerin yanı sıra açılarının da hesaba katılmasıdır. Buna göre 2-boyutlu düzlemde uygulanan polar koordinat 
sisteminde bir noktanın koordinatları, orijinden noktaya kadar olan uzaklık R ve bu uzaklığın örneğin X ekseni arasındaki açı A ile ifade edilmektedir. Polar koordinat sistemleri XY, YZ ve ZX düzlemlerinde kullanılabilir.

CNC tezgâh ve sistemlerde; tezgâh, parça ve takım olmak üzere üç ayrı koordinat sistemi mevcuttur. Tezgâhın kontrol edilen hareket yönlerine tezgâh eksenleri olarak ifade edilir. Bir CNC tezgâhında; X, Y ve Z ile gösterilen üç doğrusal hareketin yanı sıra A, B, C ile simgelenen üç dönme hareketi olmak üzere toplam altı eksen olabilir. Ayrıca ana eksen denilen X, Y, Z eksenlerine paralel olarak U, V, W ile ifade edilen yardımcı üç doğrusal eksen daha ilave olarak söylenebilir.

NC programında parçanın geometrisi, parça üzerindeki önemli noktalarının koordinatları ile ifade edilmelidir. Bu koordinatlar tezgâh koordinat sisteminden bağımsız olarak programcı tarafindan seçilen parça koordinat sistemine göre tanımlanmaktadır. Bu koordinat sisteminin orijini parçanın sıfır noktası olarak alınır. Parçanın sıfır noktası, parça üzerinde veya dışında herhangi bir nokta olabilir. Ancak eksen yönleri, tezgâh eksenleri yönünde olmak zorundadır.

Takım koordinat sisteminin orijini tayin eden takımın sıfır noktası, genelde milinin veya iş miline bağlı takım tutturma tertibatının alın yüzeyinde alınır. Takımın koordinatları bu noktaya göre seçilir. Takım boyutu temsil eden bu koordinatlar tornalamada $\mathrm{Z}$ ve $\mathrm{X}$ olarak, frezelemede yalnızca $\mathrm{Z}$ olarak ifade edilmiştir. Yukarıdaki açıklamalardan da anlaşılacağı üzerine, bir CNC tezgâhında tezgâhın sıfır noktası, parçanın sıfır noktası, takımın sıfır noktası ve eksen sınır noktası olmak üzere dört önemli nokta vardır [7].

Sinumerik 808D, DIN66217 standardına uygun bir koordinat sistemi kullanır. Bu sistem uluslararası bir standarttır ve makine ile koordinat programlama arasındaki uyumluluğu sağlar. Koordinat sisteminin öncelikli fonksiyonu, ilgili eksen üzerinde takım boyu ve yarıçapının doğru hesaplanmış olmasını sağlamaktır. Şekil 4'te DIN66217 standardına uygun eksenler ve g-kodu kodları verilmiştir. $Z$ Ekseni: İş mili ile paralel veya denktir. Pozitif yön, iş parçasından uzak bir yönü işaret eder. X Ekseni: Bağlantı düzlemi ile paralel veya denktir. $Z$ ekseni dikey olduğunda, $X$ ekseni sağa doğru döner. Z ekseni yatay olduğunda, X ekseni sola doğru döner. Y Ekseni: X ve Z eksenine dik açılı olması sonucu, mekânsal kartezyen koordinat sistemi ortaya çıkar [9].

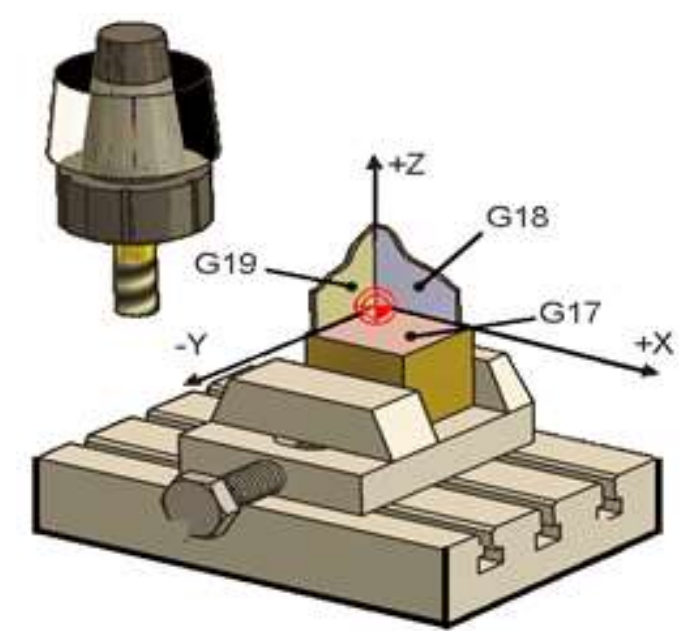

Şekil 4. DIN66217 standardı koordinat sistemi [9]

$\mathrm{Bu}$ çalışmada görüntüden alınan hareket koordinatlarının $\mathrm{CNC}$ de talaş kaldırılarak görüntünün tekrar elde edilmesi için gerekli sistem akışının blok diyagramı Şekil 5'te verilmiştir. Aşağıdaki akış diyagramında görüldügü gibi ilk işlem basamağı olarak kameradan görüntü alınması işlemidir. İkinci adım olarak elde edilen görüntü üzerinde görüntü işleme uygulamaları kullanılarak koordinatların bulunması işlemidir. Üçüncü adım olarak görüntü işleme algoritması sayesinde elde edilen koordinat değerlerinin $\mathrm{G}$ koda dönüşüm aşamasıdır. Dördüncü ve son adım olarak elde edilen G kod koordinat değerlerine göre motorlara bilgi gönderilerek belirlenen noktalar üzerinde işleme yapılması işlemidir. 
$\mathrm{Bu}$ adımların neticesinde kameradan alınan görüntüye göre prototip $\mathrm{CNC}$ tezgah ile gerçek zamanlı olarak işleme yapılması tamamlanmaktadır.

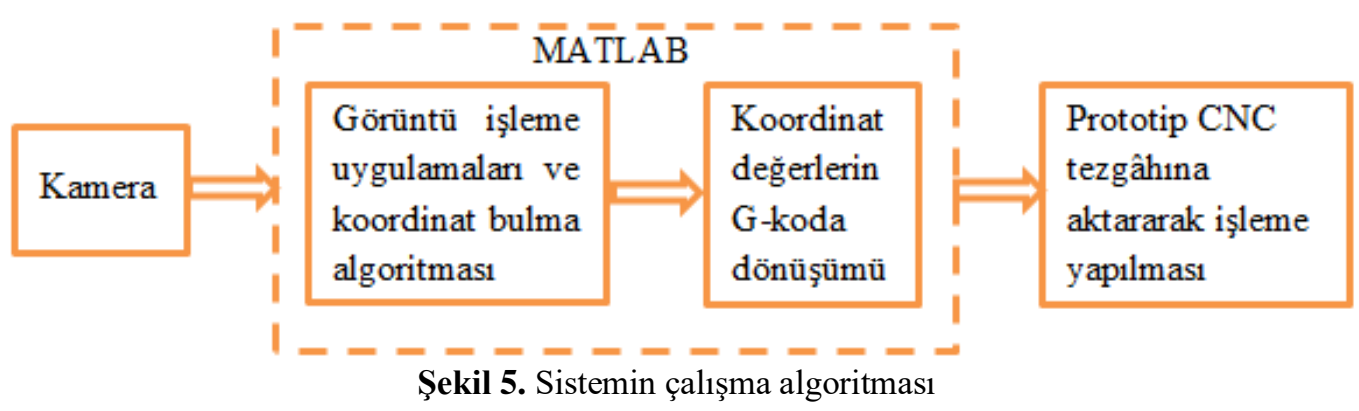

\section{Görüntü İşleme Algoritması}

Görüntü işleme, gerçek yaşamdaki görüntülerin resim haline getirildikten sonra özelliklerinin ve niteliklerinin değiştirilmesi işlemidir [4]. Görüntü işlemeyi tam olarak açılayabilmek için insandaki görme sisteminin temel çalışma mantığının bilinmesi oldukça önemlidir. İnsandaki görme sisteminin temel çalışma mantığ kısaca, gözün bir fotoğraf makinesi gibi resmi alması ve beynin de görme merkezi bu alınan resmi karmaşık bir görüntü işleme algoritması çalıştırarak görmemizi sağlayan, bir sistem olarak açiklanabilir [5]. Görüntü işleme teknolojisi günümüzde endüstriyel birçok uygulamada vazgeçilmez olarak uygulanmaktadır. Bu teknoloji, araç plaka tanıma, araç-nesne-kişi sayma, cinsiyet tanıma, nesne tanıma, kalite kontrol, otomasyon, üretim bantları, askeri, sağlık, güvenlik v.b birçok farklı alanlarda yaygın olarak kullanılmaktadır. Görüntü işleme uygulamalarında bilgisayar programları olarak genellikle Open CV, Phyton, Matlab v.b programlar kullanılmaktadır. Bu programlardan en yaygın olarak kullanılanlarından bir Matlab programıdır. Bu çalışmada, Matlab görüntü işleme kütüphanesi fonksiyonlarından yararlanılarak, görüntü işleme gerçekleştirilmiştir. Şekil 6' da görüldügü gibi kameradan resim alınmıştır. Alınan görüntüyü önce siyah-beyaza dönüştürmek için görüntü bir eşik değerinden geçirilerek birlerden ve sıfırlardan oluşan bir matris görüntüye dönüştürülür.

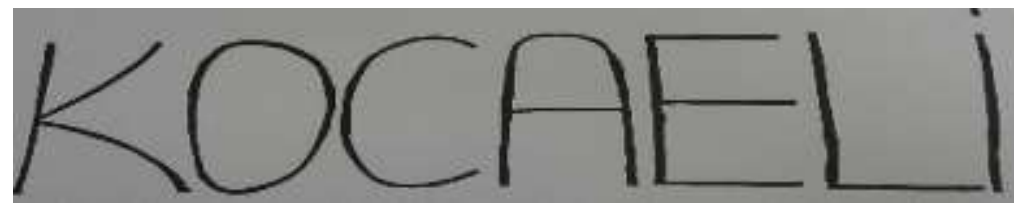

Şekil 6. Kameradan Alınan Görüntü

Elde edilen görüntü Şekil 7'den görüldügü gibi grinin tonları ayrıştırılıp yalnız grinin siyah ve beyaz seviyeleri bırakılmıştır. Bu görüntü üzerinden görüntü işleme algoritmaları uygulanmaktadır. Görüntü işleme algoritmaları ile CNC hareket yörüngelerini elde etmek için görüntünün kenar koordinatları çıkarılmaktadır. Bu amaçla görüntüden iskelet çıkarma, inceltme ve koordinat oluşturma işlemleri gerçekleştirilir.

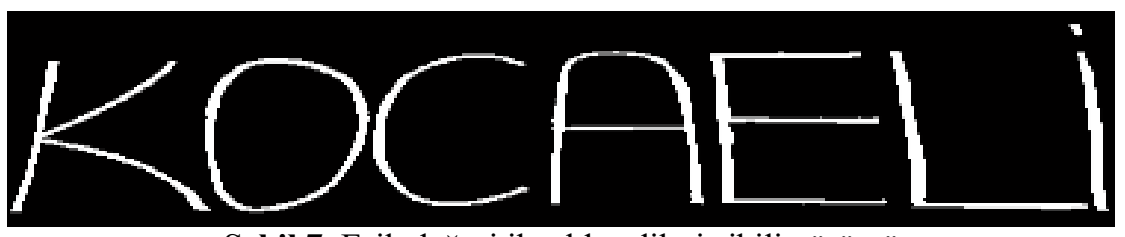

Şekil 7. Eşik değeri ile elde edilmiş ikili görüntü

\section{1. İskelet oluşturma}

İskelet oluşturmanın amacı, bir nesnenin genel şeklini temsil eden bölge tabanlı bir şekil özelliğini çıkarmaktır. Algoritma kabaca her cisim için nesnede bulunan en yakın sınır noktalarını elde edecek şekilde çalışmaktadır. En az iki en yakın sınır noktası varsa, iç nokta iskelete aittir [10]. İskelet oluşturmak için birçok teknik kullanılmaktadır. 


\section{2. İskelet oluşturma teknikleri}

Görüntü işleme uygulamalarında, en çok bilinen iskelet oluşturma için 3 temel teknik kullanılmaktadır [10].

- Sinir noktalarının mesafe haritasında tepeleri tespit etme.

- Sinir noktaları tarafindan üretilen Voronoi diyagramının hesaplanması.

- Yüzey aşındırarak inceltme.

\subsubsection{Mesafe dönüşüm iskelet oluşturma teknikleri}

$\mathrm{Bu}$ iskelet oluşturma yönteminde işaret işleme algoritması aşağıdaki gibi çalışmaktadır.

i. Orijinal (S/B) görüntü, özellik ve özellik olmayan öğelere dönüştürülür. Özellik unsurları nesnenin sinırına aittir.

ii. Uzaklık haritası, her bir öğenin en yakın özellik öğesine olan uzaklığı verdiği yerde oluşturulur.

iii. Tepeler (yerel uçlar) iskelet noktaları olarak algılanır.
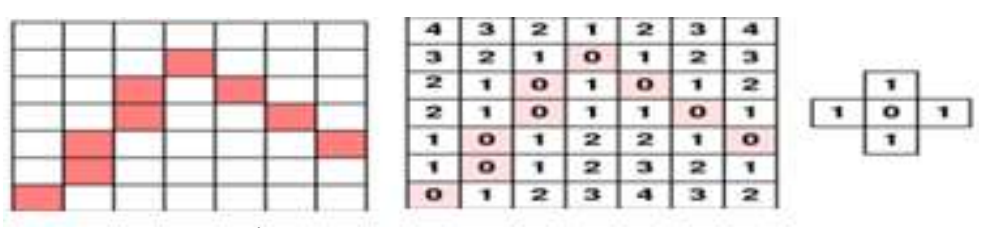

Şekil 8. İskelet oluşturma için mesafe dönüşüm [6]

Çıkarılan özellik noktaları Şekil 8'de görüldüğü gibi pembe karelerle (solda) ve şehir içi blok (veya 4 komşu) mesafeyi (sağdaki) kullanarak mesafe haritasıyla işaretlenir [10].

\subsubsection{Voronoi diyagramı}

Noktalardan ve nesnelerden oluşan kümenin komşuluk bilgilerini gösterir. Şekil 9' da görüldüğ̈̈ gibi sınır noktalarının yoğunluğu sonsuzluğa ulaşırsa, karşılık gelen Voronoi diyagramı iskelete yaklaşır.
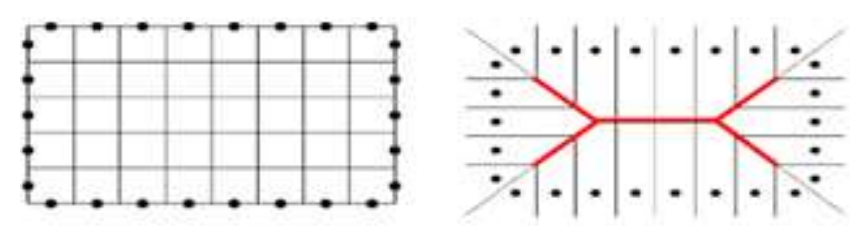

Şekil 9. Görselleşmiş voronoi diyagramları [6]

\subsection{3. İnceltme}

- Orijinal resmin topolojisini korur.

- Şekli korur.

- Nesnenin ortasında olan "iskelete" odaklanır.

- Bir piksel / voksel genişlik "iskelet üretir.

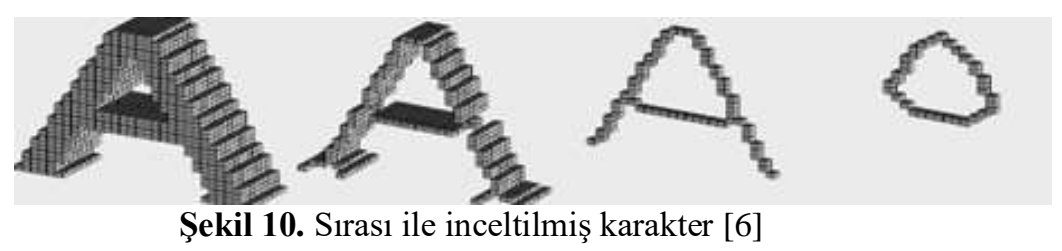

Yapılan çalışmada inceltme algoritması aşağıdaki gibi çalışmaktadır.

İnceltme algoritması için MATLAB'ın "bwmorph" fonksiyonu kullanılmıştır. Fonksiyon önce $p$ pikselinin $x_{1}, x_{2}, \ldots, x_{8}$ sekiz komşu pikselini Şekil 11' de verildiği gibi $p$ pikselinin sağından başlayarak saat yönünün tersine sırayla numaralandırır [11-12]. Burada $x_{9}=x_{1}$ olmaktadır. 


\begin{tabular}{|l|l|l|}
\hline$x_{4}$ & $x_{3}$ & $x_{2}$ \\
\hline$x_{5}$ & $p$ & $x_{1}$ \\
\hline$x_{6}$ & $x_{7}$ & $x_{8}$ \\
\hline
\end{tabular}

Şekil 11. $p$ pikselinin komşu pikselleri

\section{Koşullar:}

$\mathbf{K}_{\mathbf{1}}$ :

$X_{H}(p)=\sum_{i=1}^{4} b_{i}$, p pikseli için siyah noktadan beyaz noktaya geçme sayısı

$b_{i}= \begin{cases}1 & x_{2 i-1}=0 \text { ve }\left(x_{2 i-1} \text { veya } x_{2 i+1}=1\right) \\ 0 & \text { diğer durumlarda }\end{cases}$

$X_{H}(p)=1$

$\mathbf{K}_{2}$ :

$n_{1}(p)=\sum_{k=1}^{4} x_{2 k-1} \vee x_{2 k}$

$n_{2}(p)=\sum_{k=1}^{4} x_{2 k} \vee x_{2 k+1}$

$2 \leq \min \left\{n_{1}(p), n_{2}(p)\right\} \leq 3$

$\mathbf{K}_{31}$ :

$\left(x_{2} \vee x_{3} \vee \bar{x}_{8}\right) \wedge x_{1}=0$

$\mathbf{K}_{32}$ :

$\left(x_{6} \vee x_{7} \vee \bar{x}_{4}\right) \wedge x_{5}=0$

Algoritma birinci adımda ilk alt bölümlemede, eğer sadece $K_{1}, K_{2}$ ve $K_{31}$ koşullarının yerine getirilmesi durumunda $p$ pikselini sil. $p$ pikselini sil.

İkinci alt bölümlemede, eğer sadece $\mathrm{K}_{1}, \mathrm{~K}_{2}$ ve $\mathrm{K}_{32}$ koşullarının yerine getirilmesi durumunda

İki alt düzenleme inceltme algoritmasının bir yinelemesini oluşturur. Sonsuz sayıda yineleme belirlediğinde $(\mathrm{n}=\mathrm{Inf})$, yineleme görüntü değişmeyi bırakana kadar tekrarlanır.

MATLAB yazılan programda iskelet oluşturmada 'skel' komutu kullanılmıştır. Kameradan alınan I görüntüsüne "bwmorph(I,'skel',Inf)" fonksiyonu kullanılarak iskelet oluşturma ve inceltme işlemi birlikte elde edilmiștir. $n=$ Inf alınarak nesnelerin sınırlarındaki pikseller kaldırılır ancak nesnelerin parçalanmasına izin verilmez. Kalan piksellerden görüntü iskeleti oluşturulur. Fonksiyon görüntüye uygulandıktan sonra karakterlerin kenarlarında voronoi diyagramı aşamasından dolayı dallanmalar meydana gelmektedir. Bu dallanmalar morfolojik işlemler yardımıyla kaldırılmıştır.

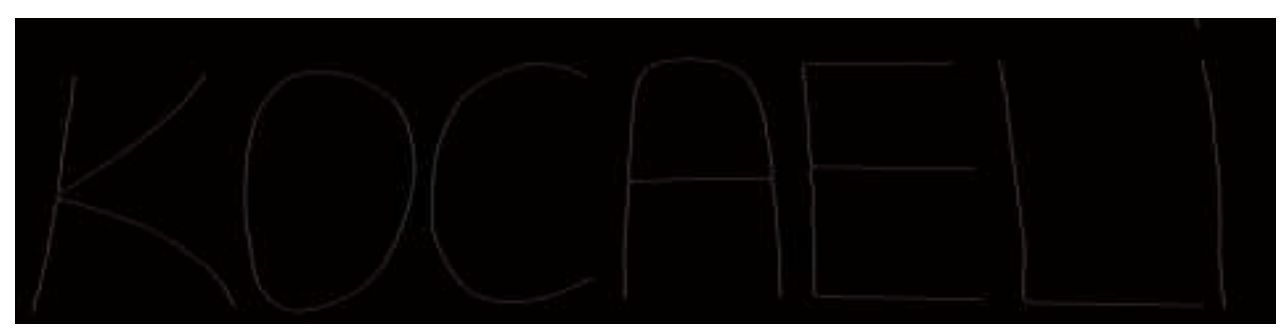

Şekil 12. Dallanmalardan arınmış görüntü 


\subsection{Koordinat bulma}

Görüntüden koordinat değerini alabilmek için, Matlab programında 'bwboundaries' komutu kullanılmıştır. Görüntüdeki her pikselin $X$ ve $Y^{\prime}$ 'de oluşan değerlerinin alınması ile koordinat değerleri bulunmuş olur. Koordinat değerlerini alabilmek için, görüntünün $\mathrm{S} / \mathrm{B}$ olmasından dolayı görüntü değişkeni ' 0 ' ve ' 1 'lerden oluşan bir dizidir. Bu dizinin sıfır olmayan elemanları piksellerin bir nesneye ait olduğu ve ' 0 ' piksellerin arka planı oluşturmasından dolayı ' 1 ' olan piksellerin koordinatları alınmıştır. Şekil 13'da, Şekil 6'daki görüntünün 'bwboundaries' komutu kullanılarak elde edilen koordinatları ile çizilmiş şekli verilmiştir [14-16]. Elde edilen koordinatların CNC'de hareket yörüngesinde kullanabilmek için filtreden geçirmek gerekiyor. Çünkü özellikle doğru parçalarının çiziminde başlangıç ve bitiş olmak üzere iki koordinat değeri yeterli olurken matlab de bu koordinat değerleri görüntünün format özelliğine göre tüm piksel değerlerini hareket yörünge koordinatları olarak vermektedir [17-18]. Bu da CNC'de aşırı bellek ihtiyacını oluşturuyor. Bu nedenle nesnenin iki pikseli arasındaki değişim miktarı belli bir $\Delta \delta$ değerinin altında ise bu koordinat noktası ihmal edilecek şekilde filtreleme yapılarak hareket yörünge koordinat değerleri azaltılmıştır. $\mathrm{Bu}$ amaçla Denklem 8 kullanılmıştır. Elde edilen filtrelenmiş görüntü Şekil 9'da verilmiştir.

$$
\begin{aligned}
& |I(i, 1)-I(i+1,1)|>\Delta \delta \text { veya }|I(i, 2)-I(i+1,2)|>\Delta \delta \Rightarrow\left\{\begin{array}{l}
\operatorname{cnc}((i, 1)=I(i+1,1) \\
\operatorname{cnc}((i, 2)=I(i+1,2)
\end{array}\right. \\
& |I(i, 1)-I(i+1,1)| \leq \Delta \delta \text { veya }|I(i, 2)-I(i+1,2)| \leq \Delta \delta \Rightarrow\left\{\begin{array}{l}
\operatorname{cnc}((i, 1)=I(i+1,1) \\
\operatorname{cnc}((i, 2)=I(i+1,2)
\end{array}\right.
\end{aligned}
$$

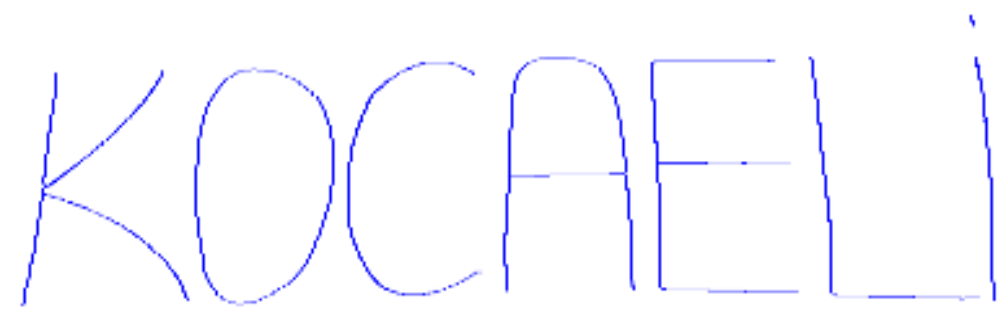

Şekil 13. Matlab ‘bwboundaries’ komutu ile alınan görüntünün çizdirilmiş hali

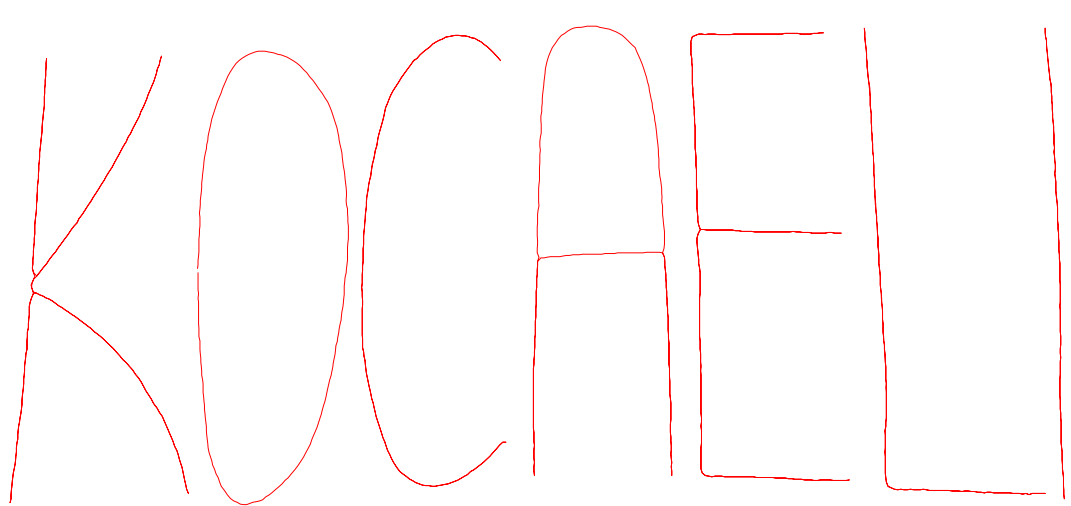

Şekil 14. Matlab ‘bwboundaries’ komutu ile alınan görüntünün filtreleme sonucu çizdirilmiş hali

$\Delta \delta=1$ alınarak filtreleme sonucu elde edilen hareket yörünge koordinat sayısı nesnelere göre Tablo 1 verilmiştir. 
Tablo 1. Görüntünün orijinal ve filtreleme sonrası CNC hareket yörünge koordinat sayıları

\begin{tabular}{|c|c|c|c|c|c|c|c|c|}
\hline & 1. Nesne & 2. Nesne & 3. Nesne & 4. Nesne & 5. Nesne & 6. Nesne & 7. Nesne & 8 . Nesne \\
\hline Orjinal & $3060 \times 2$ & $1665 \times 2$ & $2206 \times 2$ & $2592 \times 2$ & $3274 \times 2$ & $2188 \times 2$ & $71 \times 2$ & $1541 \times 2$ \\
\hline Filttrelenmiş & $433 \times 2$ & $237 \times 2$ & $313 \times 2$ & $368 \times 2$ & $467 \times 2$ & $313 \times 2$ & $11 \times 2$ & $221 \times 2$ \\
\hline
\end{tabular}

\section{CNC Programlama}

CNC makinelerin çalışma prensibi; iş parçası sabit olup, takıma, yön, konum, pozisyon, hareket yönü vererek parçayı işlemek olarak ifade edilebilir. $X, Y$ ve $Z$ düzlemlerinde ölçü (bilgi ve konum) vererek $X, Y$ ve $Z$ 'de ne kadar yol izleyeceğini makinenin anlayacağı $\mathrm{G}$ ve $\mathrm{M}$ kodları ile yapılmaktadır [19-21].

Koordinat değerlerini CNC'ye aktarabilmek için 'g-kod' a dönüştürmek gerekmektedir. Yapılan çalışmada bu işlem Matlab yazılan program aracılığıyla gerçekleştirilmiştir. Oluşturulan g-kod dosyası bir USB bellek yardımı ile CNC kontrolörüne aktarılarak makine ayarlamaları yapılarak makinenin çalıştırılması sağlanmıştır (Bir .txt dosyası oluşturulur ve alınan koordinat değerleri string olarak yazdırılır.). Şekil 15'deki koordinat değerleri ile Şekil 16'da görüldüğü gibi CNC'de işlenmiş görüntü gerçekleştirilmiştir.

\begin{tabular}{|l|l|l|}
\hline kou - Not Defteri \\
Dosya Dazen Biçim Gorunam Yardım \\
N1 G17 G500 G90 G71 \\
N2 T1 D1 \\
N3 S5000 M3 G94 F300 \\
N4 X70.00 \\
N5 Y-240.00 \\
N6 Z-10.00 \\
N20 G01 X69.85 Y-239.8500 \\
N30 G01 X69.70 Y-239.8500 \\
N40 G01 X69.55 Y-239.8500 \\
N50 G01 X69.40 Y-239.8500 \\
N60 G01 X69.25 Y-239.7000 \\
N70 G01 X69.10 Y-239.7000 \\
N80 G01 X68.95 Y-239.7000 \\
N90 G01 X68.80 Y-239.7000 \\
N100 G01 X68.65 Y-239.7000 \\
N110 G01 X68.50 Y-239.7000 \\
N120 G01 X68.35 Y-239.7000 \\
N130 G01 X68.20 Y-239.7000 \\
N140 G01 X68.05 Y-239.7000 \\
N150 G01 X67.90 Y-239.7000 \\
N160 G01 X67.75 Y-239.5500 \\
N170 G01 X67.60 Y-239.5500 \\
N180 G01 X67.45 Y-239.5500 \\
N190 G01 X67.30 Y-239.5500 \\
N200 G01 X67.15 Y-239.5500 \\
N210 G01 X67.00 Y-239.5500 \\
N220 G01 X66.85 Y-239.5500 \\
N230 G01 X66.70 Y-239.5500 \\
\hline
\end{tabular}

Şekil 15. Kaydedilen. txt dosyası

Görüntüden alınan koordinat değerlerini istenilen bir koordinat değerinden başlatılarak çizdirmek mümkündür. Bu çalışma kapsamında bunun yapılabilmesi için bir algoritma oluşturulmuştur. Ayrıca görüntüyü istenen boyutlarda oluşturmak için programa ölçekleme seçeneği eklenmiştir. Şekil 16 başlama konumu ve ölçekleme özelliği kullanılarak elde edilmiştir. Ölçekleme oranını $K$ ile kameradan alınan resmin koordinat değerleri skaler çarpılarak, büyütülmekte veya küçültülmektedir. $K>1$ alınarak boyut büyütülmekte, $0<K<1$ alınarak küçültülmektedir. Koordinat değerlerini istenilen bir koordinat değerinden başlatılarak çizdirmek için Denklem (9)' dan resmin koordinatlarının değiştirilme miktarı bulunmaktadır. Bu değişim miktarından herhangi bir resim koordinatın, CNC'de oluşturulacak yeni koordinatı da Denklem (10) ile elde edilmektedir. Bu elde edilen değer g-kod'a dönüştürülmek ve CNC'de işlenmektedir [22]. 
degisim_miktar $=$ Resim_kord $[1]-C N C \_b a s ̧ l a m a \_k o r d$

CNC_kord $[i]=$ Resim_kord $[i]-$ degisim_miktar

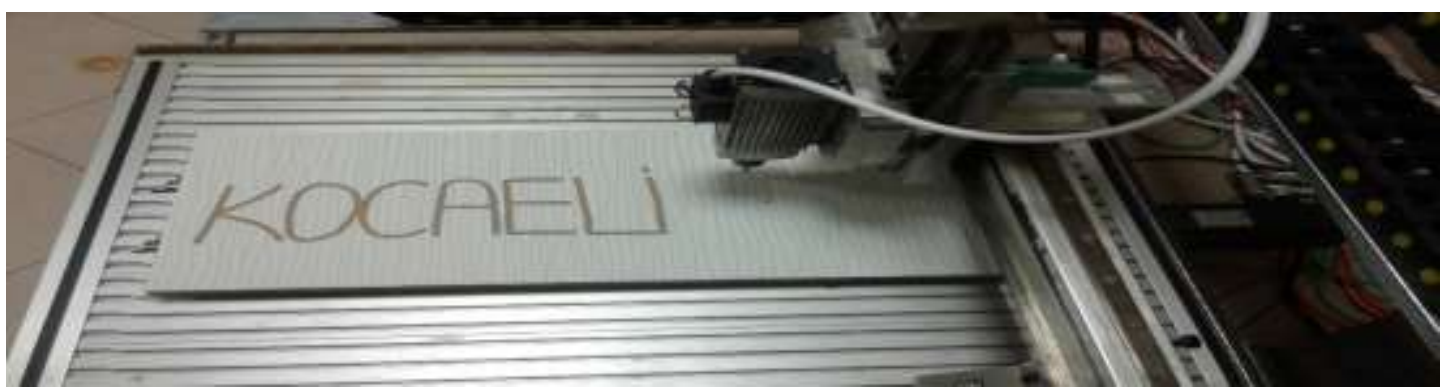

Şekil 16. Kameradan alınan görüntünün prototip CNC sistemde işlenmiş parça görüntüsü

\section{Sonuç ve Öneriler}

CNC tezgâhlara olan ilgi, akademik ve endüstriyel alandaki gelişmelere bağlı olarak her geçen gün önemini daha da arttırmaktadır. Bu çalışma kapsamında, kameradan alınan görüntünün sınır koordinatlarının hesaplanması sayesinde belirlenen şekilde CNC tezgâh tarafından işlenmesi amaçlanmıştır. Görüntü işleme aşamasında Matlab programı kullanılmış, işlenen görüntüyü istenen şekilde çizdirebilmek için Siemens'in Sinumerik 808D CNC tezgâhı kullanılmıştır. Prototip makinede gerçekleştirilen işleme çıktıları üzerinde yapılan kumpas ölçüm testleri sonucunda işlemenin neredeyse hatasız bir şekilde gerçekleştiği gözlenmiştir. Yapılan karşılaştırma ve değerlendirmelerde teorik sonuçlarla pratik sonuçların büyük oranda örtüştüğü sonucuna varılmıştır.

Bunun yanı sıra kameradan alınan bir görüntü ile Matlab üzerinde görüntü işleme alanında işlemler yapabileceği ve $\mathrm{CNC}$ tezgâhında parça işlemenin yapılabileceği görülmüştür. $\mathrm{Bu}$ işlemlerin gelişmekte olduğunu ve geliştirilebileceği, görüntü işlemenin günümüzde çoğu uygulamalara eklenebileceği elektronik cihazlar ile işbirliği içinde çalışma sağlanabileceği görülmüştür. Koordinat bulma ve bu koordinatları sıralı olarak alma konusunda detaylı araştırmalar yapılmış yeni uygulamalar ve çözümler bulunmaya çalışılmıştır.

\section{Teşekkür}

Bu çalışma, Kocaeli Üniversitesi Rektörlüğü Bilimsel Araştırma Projeleri BAP Koordinasyon Birimi Koordinatörlüğ̈ tarafindan 2015-018 no'lu proje olarak desteklenmiştir.

\section{Yazarların Katkısı}

Çalışmada tüm yazarlar eşit oranda katkı sunmuştur.

\section{Çıkar Çatışması Beyanı}

Yazarlar arasında herhangi bir çıkar çatışması bulunmamaktadır.

\section{Etik Kurallar}

Yapılan çalışmada, araştırma ve yayın etiğine uyulmuştur.

\section{Kaynaklar}

[1] Gandhi A., Sangeetha M. 2018. Development of an Image Processing Algorithm for Smart CNC Machines. IEIE Transactions on Smart Processing \& Computing, 7 (3): 232-235.

[2] Londono J.C., Mario L.E., Mora R.J.M.E.G. 2018, September. Positioning of the Cutting Tool of a CNC Type Milling Machine by Means of Digital Image Processing, In Advances in Computing: 
13th Colombian Conference, CCC 2018, Cartagena, Colombia, September 26-28, Proceedings, Springer.

[3] Lopera J.C.L., Mora J.E.G., Mesa E.M.R. 2018. Positioning of the Cutting Tool of a CNC Type Milling Machine by Means of Digital Image Processing. In Colombian Conference on Computing, Springer, Cham.

[4] Uyar E., Kavala D. 2010. 5 Eksen CNC İşleme Tezgahı Tasarımı ve PC Destekli Kontrolü-1. MakinaTek Dergisi.

[5] Kavala D. 2010. Beş Eksenli CNC Tezgah Tasarımı ve Kontrolü. Yüksek Lisans Tezi, Dokuz Eylül Üniversitesi, Fen Bilimleri Enstitüsü, İzmir.

[6] Kuncan M., Kaplan K., Ertunç H.M., Kucukates S. 2018. Design, Production and Novel NC Tool Path Generation of CNC Tire Mold Processing Machine. Journal of the Faculty of Engineering and Architecture of Gazi University, 33 (3): 1183-1199.

[7] Kuncan M. 2017. CNC Tezgâhlarında Yazı Ve Desenlerin 3 Boyutlu Karmaşık Yüzeylere Aktarılması. Doktora Tezi, Kocaeli Üniversitesi, Fen Bilimleri Enstitüsü, Kocaeli.

[8] http://www.elektrikport.com/teknik-kutuphane/matlab-ile-goruntu islemeuygulamasielektrikport-akademi/8434\#ad-image-0 (Erişim Tarihi: 01.03.2017).

[9] Siemens, Sinumerik 808D Freeze için Kullanım ve programlama prosedürleri, Eğitim kılavuzu, Versiyon 07.12.

[10] http://www.inf.u-szeged.hu/ palagyi/skel/skel.html (Erişim Tarihi: 10.02.2017).

[11] Lam L., Lee S.W., Suen C.Y. 1992. Thinning methodologies-a comprehensive survey. IEEE Transactions on pattern analysis and machine intelligence, 14 (9): 869-885.

[12] Holt C.M., Stewart A., Clint M., Perrott R.H. 1987. An improved parallel thinning algorithm. Communications of the ACM, 30 (2): 156-160.

[13] https://www.mathworks.com/help/images/boundary-tracing-in-images.html (Erişim Tarihi: 21.12.2016).

[14] Acar U. 2011. Uydu Görüntüleri ve Tıbbi Görüntülerden Benzer Görüntü İşleme Teknikleriyle Bilgi Çıkarımı. Doktora Tezi, YTÜ, Fen Bilimleri Enstitüsü, İstanbul.

[15] Tekinalp Z., Öztürk S., Kuncan M. 2013. OPC Kullanılarak Gerçek Zamanlı Haberleşen Matlab ve PLC Kontrollü Sistem. Otomatik Kontrol Ulusal Toplantısı TOK 2013, 26-28 Eylül, Malatya.

[16] Ertürk A. 2016. Bilgisayarla Görüye Giriş Ders Notu. Görüntü Eşleme, Kocaeli.

[17] Şengül Ö., Öztürk S., Kuncan M. 2020. Color Based Object Separation in Conveyor Belt Using PLC. Avrupa Bilim ve Teknoloji Dergisi, 18: 401-412.

[18] Köse İ., Öztürk S., Kuncan M. 2019. Pantography Application with Real-Time PLC Based on Image Processing in Gantry Robot System. European Journal of Technique, 9 (2): 219-229.

[19] Culha S. 2012. CNC Torna Tezgâhları için Kamera Görüntüsü ile Otomatik Parça Programlarının Oluşturulması. Yüksek Lisans Tezi, Gazi Üniversitesi, Fen Bilimleri Enstitüsü, Ankara.

[20] Kuncan M., Kaplan K., ErtunçH.M., Küçükateş S. 2016. 5 Axis CNC Precision Tire Side Machining. European Journal of Technic, 6 (2): 117-123.

[21] Kuncan M., Kaplan K., Ertunç H.M. 2015. 5 Axis CNC Tire Surface Prototype Machine. 3rd International Symposium on Innovative Technologies in Engineering and Science ISITES 2015, 3-5 June, Valencia, Spain.

[22] Mustafa D., Melih K., Metin H.M. 2013. 3 eksenli mini CNC freze tezgâhı tasarımı ve imalatı. Otomatik Kontrol Ulusal Toplantısı TOK 2013, 26-28 Eylül, Malatya. 